\title{
Strategy of using ICT in ODL to disseminate higher education in tribal communities: a case of MP, India
}

\author{
Subash Ranjan Nayak
}

$A R D, R C$ Bhopal, IGNOU, Bhopal, India

Nikhil Kant

Research Scholar, SOMS, IGNOU, New Delhi, India, and

Kumari Anjali

Research Scholar, SOS, IGNOU, New Delhi, India

\begin{abstract}
Purpose - The purpose of this paper is to make an assessment of the challenges in disseminating higher education to the learners in tribal communities, and problems solving capacity of Open and Distance Learning (ODL) by strategically making use of Information and Communication Technology (ICT) taking a case of Madhya Pradesh (MP), which is the most tribal dominated state of India. The paper offers valuable insight in to the usage of ICT as a strategy for the ODL system presenting an account of how it can be utilized effectively to disseminate higher education in tribal communities.

Design/methodology/approach - Exploratory and descriptive techniques were utilized in this paper adopting the research strategy of case study in terms of the strategic potentialities of ICT in disseminating higher education in tribal communities by ODL using it as a strategy for their empowerment and development. Findings - The findings of the paper reveal that dissemination of higher education in tribal areas is a challenging task especially due to their socioeconomic conditions and ethno cultural settings in addition to numerous infrastructural and access related issues. In view of the need of integrating education with the Indigenous perspectives, ICT can be used as an effective strategy by ODL for disseminating higher education amongst learners in those communities by reaching out to them.

Practical implications - This paper concludes that ICT can help ODL immensely in developing countries such as India strategically in reaching the tribal learners surpassing financial and geographical constraints with a learner centric approach increasing the capacity, quality and cost effectiveness of education system bringing the concept of strategy to center stage, at a time when ICT has fundamentally changed the strategies of different sectors including education with the unprecedented growth in its use.

Originality/value - This paper concludes that ICT has fundamentally changed the strategies of different sectors including higher education with the unprecedented growth in its use. It also concludes that Indian higher educational sector faced with multitude of challenges is not insulated from the effect of ICT, and its emancipatory and transformative potentials in higher education can play a major substantive role by extending support to meet the increasing higher educational needs of the tribal communities by sufficiently embedding it so that their greater contributions to the Sustainable Development Goals (SDGs) can be ensured.
\end{abstract}

Keywords ICT, ODL, Open and distance learning, Strategy, Sustainable development goals, Tribal communities

Paper type Case study

(C) Subash Ranjan Nayak, Nikhil Kant and Kumari Anjali. Published in Asian Association of Open Universities Journal. Published by Emerald Publishing Limited. This article is published under the Creative Commons Attribution (CC BY 4.0) licence. Anyone may reproduce, distribute, translate and create derivative works of this article (for both commercial and non-commercial purposes), subject to full attribution to the original publication and authors. The full terms of this licence may be seen at http:// creativecommons.org/licences/by/4.0/legalcode
Received 14 May 2020 


\section{AAOUJ}

15,2

\section{Introduction}

The emergence of ICT has fundamentally changed the strategies and practices of not only businesses and governments but education sector also. While the world has moved to embrace digital advancements at a very rapid pace, the role of ICT in education in general and higher education in particular has become increasingly important with the unprecedented growth in its use in teaching/learning, research and allied activities transforming the way of dissemination of knowledge today (Kant, 2020). Indian Government, with multitude of challenges with respect to infrastructure/socioeconomic/ linguistic/physical barriers for people willing to have access to education (Bhattacharya and Sharma, 2007), too has not remained insulated from its effect with the rising expectations of transforming the educational scene in the country. The emancipatory and transformative potentials of ICT in higher education in India can play a major substantive role by extending its support to meet the increasing higher educational needs of the huge population through ODL system. It can be used effectively to overcome the issues of cost, scarcity of teachers, quality and barriers of time and distance (McGorry, 2002). Mooij (2007) argues that differentiated ICT-based education can be expected to provide greater reliability, validity, efficiency of data collection, ease of analysis, evaluation and interpretation at any educational level. UNESCO (1997) has also stressed that with the increasing needs of education, ODL in developing countries is considered an important tool to reach the learners to meet their needs which have remained unmet due to different financial and geographical constraints underscoring the significance of the ICT usage in order to benefit them. ICT by bringing about a learner centric approach can present it to be harnessed for multiple purposes including but not restricted to increasing the capacity and cost effectiveness of education and training systems and enhancing the quality of higher education where the concept of strategy takes center stage (Kant, 2020).

India has a GER of only $24.5 \%$ in higher education in the age category of 18-23 in comparison to the developed countries with $90 \%$ or even more. The situation is more dismal for the Scheduled Tribes with only $14.2 \%$ where male constitutes $15.6 \%$ and female $12.9 \%$. However, the silver lining is provided by the ODL system with $12 \%$ enrolments of the total higher education enrolments contributing substantially to enhance the GER providing thereby wider opportunity of learning to the learners in disadvantaged communities (MHRD, 2016). Dissemination of higher education in tribal areas is a challenging task especially due to their socio-economic conditions and ethno cultural settings in addition to numerous infrastructural and access related issues. The present paper attempts to make an assessment of the challenges in disseminating higher education to them and problems solving capacity of ODL by strategically making use of ICT taking a case of Madhya Pradesh (MP) which is the most tribal dominated state of India, focusing on assess the role of ICT in higher education in tribal areas, keeping in view that advancements in ICT and their adoption can influence the development of ODL in these areas, by throwing light on different ICT tools used in recent times for the delivery of instructional content and student support services by IGNOU, a leader in Indian ODL higher education landscape. This way, the paper presents an analytical view of the interventions of ICT in ODL system in disseminating higher education in tribal communities for their empowerment and development. In view of the need for integration of education with the Indigenous perspectives, this study based on both exploratory and descriptive methods assesses the potential of ICT in disseminating higher education in tribal communities by ODL by using it as a strategy. To that end, the following sections elaborate on the objective and research method employed in the study, followed by sections throwing light on the efforts of providing clarity in the understanding of the definition of Indigenous and tribal peoples, their status, ICT and its adoption as a strategy, Indian landscape of higher education and ODL and strategy of using ICT in ODL for the dissemination of higher education in tribal communities taking a case of MP, India. In the end, there is a section with 
discussions and concluding remarks. The paper promises to be useful for educational administrators in ODL, policymakers, Government departments, NGOs and researchers.

\section{Objective of the study}

Given that there is plethora of challenges in disseminating higher education in tribal areas in India, there is a pressing need to evaluate the effectiveness and availability of tools that can be helpful in overcoming these challenges. This study aims to assess the challenges in disseminating higher education to learners in tribal communities and problems solving capacity of ODL through strategic use of ICT by taking a case of Madhya Pradesh (MP) which is the most tribal dominated state of India. This study, therefore, is an attempt to provide a rational understanding of the use of ICT for dissemination of higher education in tribal communities as an appropriate strategy of ODL system.

\section{Research method}

This study adopted the research strategy of case study using exploratory and descriptive techniques for assessing the potentialities of ICT in disseminating higher education in tribal communities by ODL using it as a strategy for their empowerment and development. The study uses primary as well as secondary sources of data. While data from primary sources comprised admissions data requested and received from IGNOU Regional Centre (RC) at Bhopal in the state of MP, specific and general observations, participation in meetings as officials of IGNOU at different study centers and discussions with the learners including prospective learners in tribal dominated areas of MP; the data from secondary sources comprised extant literature primarily including relevant reliable reports, articles and books. Further, quantitative data were used in this paper as evidence to support arguments by means of quantitative methods as and when found appropriate in the context of the objective of the study.

\section{Indigenous and Tribal Peoples: a general denominator}

The term "Indigenous and Tribal Peoples" is used as a general denominator for distinct peoples pursuing their own concepts and way of human development in a specific geographical, socioeconomic, political and historical context. Their history has been fraught with continuous struggles for maintaining group identity, languages, cultures, beliefs, ways of life, and rights over their lands, territories and natural resources, having much in common with other socially marginalized segments such as weak political representation/ participation, restricted access to social services, and discrimination/exploitation in labor markets etc. (ILO, 2018). Salick and Byg (2007) underscore that social and institutional discriminations have been responsible for victimization of the tribal communities in the era of rapid globalization across the world diminishing their engagements in the discourse of development. However, Etchart (2017) argues that their co-evolution with the natural settings and unique capability of conserving the natural ecosystem along with its services cannot be ignored.

A population more than 370 million spread across almost 70 countries, "Indigenous and Tribal Peoples" without any universal definition got much sought-after support from a practical approach of International Labour Organization (ILO) Convention 169 which provided objective and subjective criteria to identify this population which is known by native peoples, aboriginal peoples, first nations, hunter-gatherers, adivasi, janjati or hill tribes. The convention used the inclusive terminology "Indigenous and Tribal Peoples" for ensuring same set of rights to Indigenous and Tribal peoples. They collectively pursue fundamentally 
AAOUJ

15,2

192 different livelihood strategies, values and aspirations from other sections of society maintaining their identity distinctness from other groups of the society (ILO, 2018).

While almost all of the 17 Sustainable Development Goals (SDGs) - adopted in 2030 Agenda for Sustainable Development of the United Nations by member countries for ensuring sustainable social-environmental-economic development to enhance human welfare and planet's longevity with the ambitious plan to achieve them by 2030 - indirectly relate to the tribal communities seeking their engagements in recognition of their significance roles, some specific goals such as Goal 4 relates directly by stressing to achieve inclusive and equitable quality education simultaneously promoting lifelong learning for all, and SDG 16 relates directly by aiming to promote peaceful and inclusive societies with the ambition to ensure sustainable living and the holistic development of the society providing access and build effective and inclusive institutions at different levels (UN SDG Knowledge Platform, no date; Bordoloi, 2020; Kant and Anjali, 2020). There are various studies undertaken in the context of their sources of income finding that majority of these sources are related to the natural resources. They value their ecosystems more than their economic gains underscoring the complexities existing in their cultural connections to natural resources. They follow a selfgoverned sustainable economic model with highest respect to natural resources although they differ significantly from one another in terms of their habitats and way of living (ILO, 2017) Indian landscape of Tribal Communities.

Following the footsteps of the events in African and South-East Asian countries, tribal peoples in India also encountered, in the past, attempts of separating them from their own surroundings and ecosystems through different regulations. But in recent times, introduction of inclusive policies with their greater participation have had substantive positive effect where Government has attempted to directly engage them which has consequently spread more awareness amongst them about the benefits arising from inclusive policies (UNEP, 2013; Harisha et al., 2016).

Karlsson (no date) informs that India, collectively with a number of other Asian countries cast its vote favoring the UN Declaration on Rights of Indigenous Peoples in 2007 as a nonbinding international instrument. India, as a true representative of various developing countries, houses one of the largest indigenous populations of the globe with 461 such ethnic groups recognized as Scheduled Tribes (ST) generally referred to as "adivasi" in common parlance. They comprise $8.2 \%$ of the total national population estimated to be 84.3 million. However, it excludes a number of ethnic groups yet to be recognized as STs officially which otherwise is estimated to be tribal groups is 635 with largest concentrations in the usually referred "central tribal belt" from West Bengal to Rajasthan, and North-East states whose land and self-governance rights are protected through legal and constitutional provisions in the 5th and 6th Schedules. Karlsson (no date) further informs that Indigenous, tribal and adivasi terms are used interchangeably in India making international legislation/policies related to indigenous peoples applicable in their contexts. The official stand of the Indian Government allows these STs to enjoy a set of constitutional provisions and reservation quotas in different sectors including education (Karlsson, no date). This way we come to know that different tribes have their own distinctiveness though they all are represented by a common denominator as ST in Indian context. They display differences in their socio-cultural set up and identity while engaging in common economic activities in a particular region. However, these differences, while considering a tribal region as a compact unit to study, bring to our attention that multitude of external factors are responsible for these differences and disintegrations amongst different tribal communities.

The programs of ILO under effect of its Convention 169 have tended to focus on the potentials of tribal communities and their realization to facilitate sustainable growth by ensuring their consultations and participations. Sustainable Development Agenda 2030 adopted for the period of 2015-2030 too has proposed 17 Goals with 169 Targets to be 
achieved through equal access to knowledge and inclusive and equitable quality education for tribal peoples with others. World Conference on Indigenous Peoples under the aegis of the UN has tried to underscore the significant role of tribal communities in sustainable development. Paris Climate Accord under the UNFCCC and Sendai Framework for Disaster Risk Reduction with their goals set for next decades highlight the Government engagements with tribal communities as well as stakeholders in designing and implementing policies. The various national level policies along with international intergovernmental and nongovernmental efforts including but not limited to the SDGs, Convention on Biological Diversity (CBD), Multilateral Environmental Agreements (MEAs) and assessment reports of IPCC, have emphasized the significance of tribal communities amply revealing the global priorities in recent times. "Teaching and Learning for a Sustainable Future: A Multimedia Teacher Education Program" propagated by the UNESCO too has highlighted their potentials with respect to sustainable future (Kim et al., 2017).

\section{Adoption of ICT as a suitable strategy}

Abeywardena (2017) posits that instead of underestimating ICT, it should be considered significantly useful for the purpose of mainstreaming process of OERs providing important underpinnings to ODL which are predominantly digital and demands higher bandwidth. While Shrestha et al. (2010) stressed upon the significant issue of poor Internet connectivity in developing countries such as India due to lesser bandwidth and lack of appropriate infrastructure for optimally utilizing ICT more particularly in remote areas affecting the teaching-learning experience negatively; Pugoy et al. (2016) to have argued in favor of enhancing optimally the utilization of ICT in syncing OERs In future keeping in view the limited bandwidth. Nonetheless, Tait (2018) cautions that open universities, facing severe competition from local as well as foreign universities entering the higher educational arena technologically equipped sufficiently to harness the strategic benefits of ICT to outpace them in terms of access and flexibility. Bordoloi (2018) too argues that inclusive growth demands establishment of greater access in addition to equality, quality, and expansion - highlighting further the need for the ODL institutions to be comfortable with the use of ICT in the present technology-based era, further stressing the significance of ODL in facilitating and strengthening the Indian higher education system, given its capability to provide quality and affordable education at the doorstep of the learners in addition to encouraging people for transferring knowledge and innovative ideas using ICT.

ICT cannot be a panacea for different educational problems but its usage and applications are expected to play significant role as essential tools for teaching-learning process as the process is going to be highly challenging in our society with the advent of diverse technology options and new learning concepts. Innovative technological developments providing new possibilities to ODL system have simultaneously challenged ODL system to explore more avenues of using ICT in their practices to enhance access and reduce costs. Research provides evidence that ODL system can, in addition to plethora of benefits, negate the negative impacts of higher fixed costs than conventional system with the help of increased enrollments, access, quality and resources (Jung, 2005a). Indian ODL system is in dire need of ridding its inadequacies in order to integrate new innovative models, e.g. MOOC \& OER, for the purpose of meeting the increasing unmet needs (Gaba and Li, 2015) of its huge populations including substantive tribal population.

There has been abundant emphasis in the field of strategic management on defining strategy underscoring the significance of formulation of appropriate strategy for any organization seeking directions in order to develop and implement practices for achieving their goals harnessing resources and environment. Strategy is generally known for its capability to ensure the directions any organization ought to move for sustainable growth. It 
AAOUJ

15,2

194

is a formula to compete with other organizations by setting the goals, determining the policies, and attaining the goals by using the linkages of organizations and their external environment (Porter, 1980). A strategy reflects a human efforts of meeting the desired outcomes of better shaped future though the real world suffers from the scarcity of resources (McKeown, 2012). The findings of the studies in the field of strategic management suggest that intangible resources, such as ICT, are found to be strategically more significant than tangible resources (Barney, 1991; Hitt et al., 2001), the configuration, utilization and utility of which acting as the underpinnings for competitive advantage hint at the competitiveness of the organization which use these resources effectively and efficiently. ODL system which has evolved as a new teaching model in previous few decades has potentials to help people teach/ learn any place and at any point of time with the adequate support of multimedia and technology (Faridi and Ouseph, 2014). ICT, in that context, needs to be utilized as a strategic resource by ODL system which it should use in combination of other resources and capabilities (Kant, 2020) to disseminate higher education in tribal communities effectively and efficiently.

\section{Indian landscape of higher education and ODL system}

India is known as a country which has multi-cultural and plural societies having the second largest population in the world possessing the third position amongst the largest higher education system following the US and China (Jayaram, 2007). Indian education system in line with its growing economy is known to be one of the fastest growing systems on the planet where increasing pressures - of the youth graduating from their school studies; opening up of the economy; liberalization and liberal educational policies; greater need for continuing professional development, access, equity especially for the disadvantaged sections of the society; and developments in ICTs - have influenced to take recourse to ODL in the country (MHRD, 2016). Competing with the institutions in the fastest growing ODL system across the globe, ODL system in India has acquired recognition as the second largest in the world which has greatly benefitted by the definitive plans of action in order to achieve this tremendous growth (Garg et al., 2006). This system in India has support of about 11,000 study centers as well as 70,000 academic counselors catering to the specific academic needs of its students enrolled in the 17 Open Universities reaching to all the corners of the country offering varieties of academic programs which are not of general nature only but of professionalvocational-technical nature too (UGC, no date). ODL system in India has garnered substantive support to emerge as an important mode of teaching/learning to diverse sections of society because of the changing dynamics of ODL system in the last six decades when developments and higher use of ICT have helped blur the boundaries of classroom or campus (UGC, no date), following what has been happening in other parts of the world in the context of ODL system. With its wider network and coverage, ODL system in India has continuously been trying to overcome the gaps between those who have access to education and those who have not.

Higher education system in India is said to be one of the largest in the world. While in 1947 when India attained independence, it had only 20 universities and 500 colleges with 0.1 million students which has expanded substantially turning out to be one of the largest higher education systems having 911 universities in 2019, the details are presented in Figure 1. However, this substantial growth is yet not sufficient to cater to the huge population willing to get higher education and this number still runs short of the requirement by huge margin in India.

The application of ICT in higher education has not only brought about diversification in higher education but has also fostered new avenues for international mobility of traditional and non-traditional students (Pegu, 2014). But the fact of the matter is that the higher 


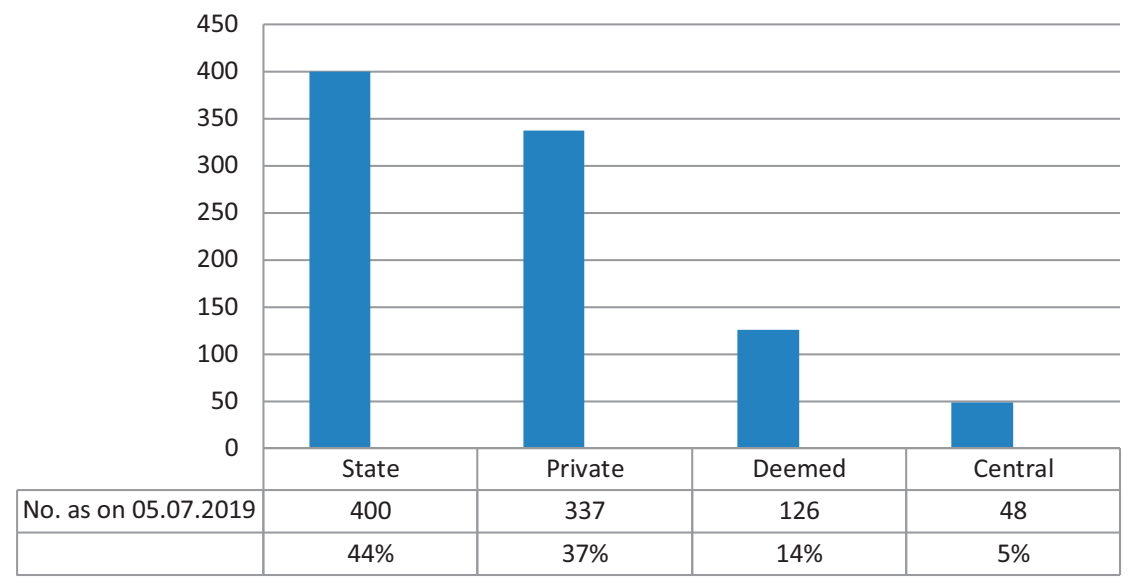

Source(s): https://www.ugc.ac.in/oldpdf/Consolidated\%20list\%20of\%20All\%20Universities.pdf
Strategy of using ICT in ODL

195

Figure 1. Total Universities in India offering higher education

education system in India has always suffered from the inadequate access and uses of ICT leading to undesirable inequity. Believing that ICT can transform educational scene in the country, the sense of urgency and gradual implementation of ICT in higher education have led many universities and colleges into more action-oriented adaptation approach (Schmidtlein and Taylor, 2000).

India faces major concerns arising from multitude of challenges and weaknesses with respect to infrastructure, socio-economic, physical and linguistic obstacles for the learners (Bhattacharya and Sharma, 2007), cost, inadequate teachers, quality of education and time and distance barriers which can be overcome by ODL system as an appropriate way (McGorry, 2002). On these lines, in order to negate the effect of the inadequacies in the Indian higher education system in terms of access and equity, Government has established 14 state open universities in different Indian states to disseminate higher education through ODL system and 1 central university, i.e. Indira Gandhi National Open University (IGNOU) (Chaturvedi and Nayak, 2017) established in 1985 to enhance educational access and equality and to promote, coordinate and determine standards in ODL system. It provides innovative and need based general as well as continuing education to all, including tribal peoples based in remote areas, for the purpose of providing educational and professional progression. It practices a flexible and open educational system with respect to methods, place, coursecombinations, eligibility, age, evaluation, etc. currently serving the cumulative strength of more than 3 million learners through 21 Schools of Studies, 67 RCs and around 1,961 Learner Support Centres across the country with the empanelled academic counselors in excess of 35,300 drawn from conventional higher educational institutions, professional organizations, industries etc. (IGNOU, 2020).

In the Indian context, Indira Gandhi National Open University (IGNOU) which was established by a Parliamentary act by the Indian Government in 1985 with the objectives to advance and disseminate learning/knowledge by different means including ICT providing opportunities for higher education and educational well-being of different communities of the entire population by encouraging ODL system in India, has become the largest university on the planet. IGNOU, starting with an enrolment of 4,528 learners in 1987, has achieved the enrolments of 1,293,550 learners in 2019, comprising $45.4 \%$ female learners, $40.2 \%$ rural learners, $14.8 \%$ SC learners and $10.2 \%$ ST learners (IGNOU, 2020). 


\section{AAOUJ}

15,2

\section{Strategy of using ICT in ODL for tribal areas: a case of MP}

Tribal peoples with the possession of traditional knowledge including traditional ecological knowledge (TEK), a tacit knowledge which can be preserved and transmitted through effective use of ICT in a cost effective manner reinforcing their cultural and geographical interactions and collaborations, can be purposefully engaged for the improvement of scientific ecosystem models extending significant support to policymakers, decision-makers, and also to these tribal communities in building suitable and viable sustainability models (Finn et al., 2017). Negi et al. (2017) support it further suggesting integration of their traditional knowledge with western scientific knowledge for using it for effective climate actions and sustainable development. The strategies for the ODL system and its institutions should be in line with the expectations of varied stakeholders (Kant, 2019) for the purpose of providing optimum technological and employability skills by adopting collaborative approach instead of mere coordination or cooperation approach in order to meet its strategic vision-mission-objectives-goals (Faridi and Ouseph, 2014).

With the "teaching-learning facilitation-facilitated and supported enquiry" transformation of learning paradigms, ODL system has emerged in previous few decades as a highly effective mode of imparting education all over the world (Brown, 2006) to all including learners in tribal communities. Having started from the simplest correspondence form, it has continuously embraced newer forms with the support of emerging ICT which helps it serve varied and ever increasing needs of learners. Distinctive characteristics of ODL system have helped it expand substantially by catering to a huge populace of current and prospective learners with greater use of ICT while globalization of institutions requires it to adopt proactive approach for addressing a number of challenges related to emerging needs, equity and human rights (Jung, 2005b) of all, including tribal peoples.

ODL as an educational process underscores almost all teaching and learning activities happening through artificial print and electronic medium in view of the fact that the ODL teachers and learners are separated in terms of time and space (UNESCO, 2002), and thus, it is being considered to be a viable alternative of the conventional institutions which, in recent times, has started to face difficulty in maintaining quality because of the spurt in the willing learners exceeding the he capacity of already over-crowded classrooms (Ural, 2007). ICT, which is found to have substantial effect on ODL system facing tough competition from the conventional learning system, has helped ODL system receive acceptability across the globe, in recent times, as an effective mode of teaching/learning. The much hyped fourth industrial revolution showcasing promises with respect to emerging technological innovations is also being believed to revolutionize ODL system significantly transforming the way instructions and learning materials are delivered (Kant, 2020).

In addition to providing fee exemption and establishing Special Study Centres (SSC) for STs in the remote and rural areas to enhance access and reach, IGNOU has provided RCs and SSCs with computer-based network connectivity for interactive digital content transactions, in order to meet the expectations of providing education to the marginalized sections. IGNOU conducts interactive radio counseling not only from its studio at its Headquarters in Delhi but also across the country including MP through 15 Gyan Vani FM radio stations. Gyan Darshan, a milestone in Indian educational television, since its inception in 2000 has been offering the best of educational programs as a 24 -h educational channel, also including daily live interactive teleconferencing and promotion of Government Schemes/initiatives to spread awareness on important issues. The redesigned/reactivated educational resource portal e-GyanKosh in the form of Digital Repository with enhanced features, such as FlexiLearn platform and IGNOU-YouTube Collaboration, has garnered more popularity amongst remote learners facilitating them in accessing the self-learning materials of GNOU. These measures emphasize the development of interactive multimedia and online learning as value addition to the 
conventional ODL mode by attaching modern technology-enabled education broadening the framework of blended learning (IGNOU, 2020).

Wolcott (2003) has elaborated on the immense contributions of the growth in ODL system to the developing countries in meeting the targets related to expansion of higher education to bring it to all over the country for sustainable development by getting commensurate support from ICT in an effective and efficient manner. ODL system has become, by virtue of having more flexibility and providing greater interactive learning experience, an important policy choice in the field of higher education by majority of Asia and the Pacific (AP) region Governments underlining the significant potentials of ODL system (Jung, 2005b) which can play the leadership role and attain competitive advantage (Siaciwena and Lubinda, 2008) receiving support from the advancements in ICT. With the 251 (academic/ professional/ vocational/ awareness/ skill-oriented) certificate/Diploma/Graduate/Post-Graduate/M.Phil/ Doctoral programs, IGNOU strives to meet the diverse needs of the disadvantaged sections of society by introducing modular programs integrated with various entry-exit opportunities to ascertain a flexible environment of learning, also providing a robust integrated platform/ portal using ICT involving Massive Open Online Courses (MOOCs) e-content. The testimony to its success is enrolment of learners in excess of 90,000 on SWAYAM Platform. Similarly, IGNOU has engaged itself as the national coordinator for five channels of SWAYAM PRABHA which is a project to telecast $24 \times 7$ high quality educational programs on 32 free Direct-to-Home (DTH) channels with the help of the 2 GSAT-15 transponders with universal coverage in the entire country. This way, IGNOU succeeds in providing multi-channel/ multiple media teaching-learning packages not only for instruction delivery but for selflearning also. Summarily, the self-instructional print materials/laboratory/hands-on experiences/counseling/tutoring are supported by the effective use of ICT including but not restricted to digital- CDROM \& AV materials, MOOC Videos, broadcasts through radio/ TV, Web casting, online mentoring, tele-conferencing, video-conferencing, interactive radiocounseling, internet-based learning, instant messaging through mobile phones, and social media support in order to enhance the learning experience. The summative evaluation has also been added with the alternatives such as On-Demand examination using ICT effectively (IGNOU, 2020).

Pedro (2001) argues that the focus is often more on end products than on the premises and processes behind an effective incorporation of ICT in teaching and learning. IGNOU has rolled out Web Enable Academic Support (WEAS) Platform for learners. IGNOU has also introduced mobile learning in remote tribal areas which lack the presence of higher education institution extensively using ICT based mobile learning for Digital Literacy Campaign as its initiatives to provide free and high quality education to such learners in addition to other promotional schemes for social welfare. A mobile application "IGNOU e-Content" providing learners with the on-the-go easy access to IGNOU learning materials enabling them to learn anytime/anywhere; and an Internet web radio service "Gyandhara" providing useful and affordable way of reaching students with the streaming of Gyan Vani contents, are other major initiatives IGNOU has taken using ICT effectively (IGNOU, 2020).

IGNOU (2020) also reports several other ICT initiatives of IGNOU such as Development of Integrated Web-Support Portal, Samarth -a Government of India initiative, Migration from Online Admission System (OAS) to Cloud based portal, Application for Online Question Paper Delivery System (OQPDS), might not appear to be directly benefitting the tribal learners but their indirect significant effects cannot be ruled out. Enrolment trend of IGNOU in terms of "area of living in 2019" is displayed in Figure 2.

However, the enrolment trend of IGNOU in terms of "social category in 2019" displayed in Figure 3 reflects the effect of its major initiatives for the improvement of participation of socially backward communities in higher education. 


\section{AAOUJ 15,2}

198

Figure 2.

Enrolment trend of IGNOU in terms of area of living in 2019

Figure 3.

Enrolment trend of IGNOU in terms of social category in 2019

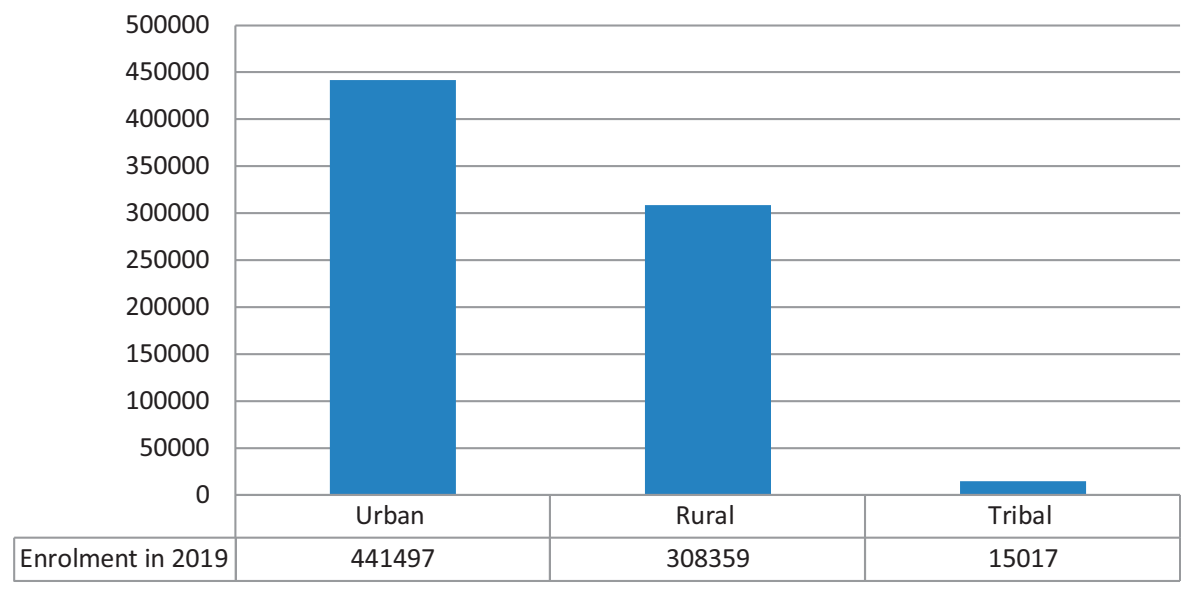

Source(s): IGNOU (2020)

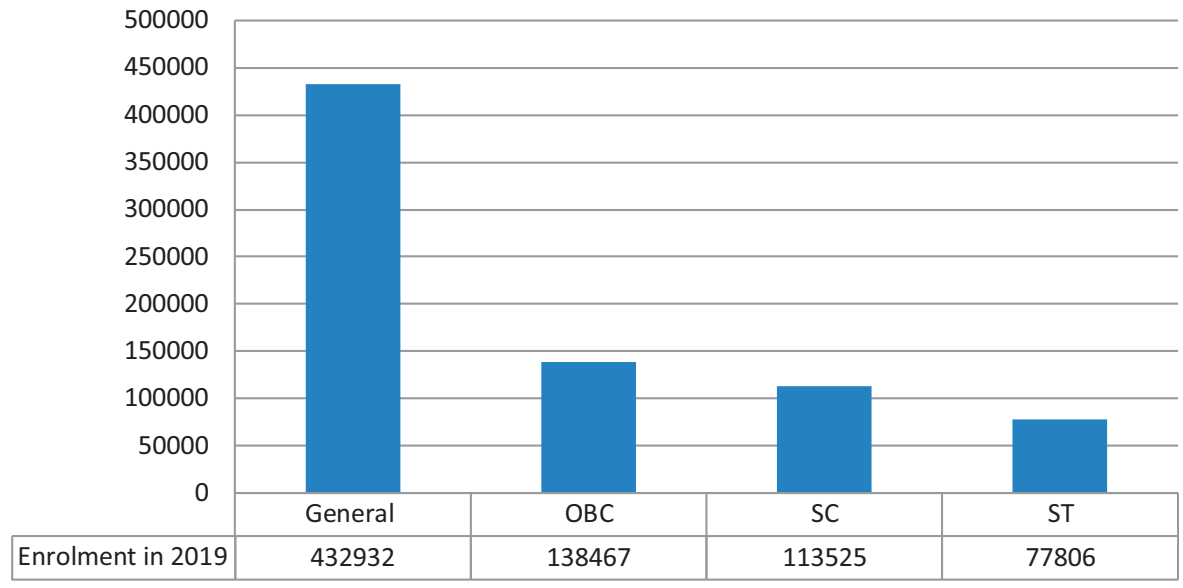

Source(s): IGNOU (2020)

Studies (e.g. Menguc et al., 2010) suggest that competitive advantage can be ensured by pre-empting other organizations with similar objectives by securing first mover advantage - efficiency legitimacy as a good corporate citizen, and using cutting-edge technology in addition to several others. ODL system, which has flourished using ICTs, adequately promises to have potential to address the issues of access in order to enhance capacity building (McQuaide, 2009). Realizing that recognition of ODL depends heavily on its flexibility and learner-centric approach, IGNOU as the Apex ODL institution in India has acquired leadership position by improving learners' satisfaction, also acquiring the status of guiding body and source of inspiration for other ODL institutions in India (IGNOU, 2020).

In order to bridge the gap with its learners, IGNOU has developed the mechanism of handling their queries and grievances not only through modes such as post/in person but also through fax/ e-mails/SMS/Social Media/telephone/Interactive radio-television sessions/on-line 
Portals/iGRAM using ICT effectively. IGNOU also has also started providing its youth learners in remote areas with the right opportunities in their careers at the right time through the National Career Service Portal (NCS), a national ICT based portal of Ministry of Labour and Employment, Government of India (IGNOU, 2020).

IGNOU has tended to cater to the unmet needs of the varied groups of learners with different social, economic and regional backgrounds including tribal communities suffering from low literacy, through an extensive national/international network in ODL Mode by offering programs, such as Post Graduate Diploma in Social Work among tribes, to facilitate social Work and skill up gradation in tribal areas. IGNOU endeavors to enhance access, analyze and document the TEK, possessed by tribal peoples and has set up centers for vocational education and trainings through ODL, in addition to Mobile Study Centers and various Learner Support Centers connected with satellite downlink facility \& Direct To Home (DTH) facility to empower them. IGNOU established Educational Development of the North East Region Unit (EDNERU) for enhancing educational and vocational training related access and equality to the huge uneducated tribal population constituting almost $4 \%$ of the national population to overcome physical and geographical barriers using teleconferencing for interactions, debates and discussions (IGNOU, 2013). Initiatives such as launch of Edu-Sat (an educational satellite) in 2004 and establishment of Inter-University Consortium gave IGNOU an impetus to begin a new era of technology-enabled learning ecosystem in India, followed by linking its centers with an active two-way video-conferencing network connectivity facilitating interactive digital contents transactions. Further emphasis on developing interactive multimedia and online learning in order to add more value to existing traditional distance education by means of modern technology-enabled learning is being laid within the framework of blended learning (IGNOU, 2014).

Madhya Pradesh (MP) is known to be a state with maximum tribal population amongst various states of India which are being served by different Regional Centres of IGNOU. In Madhya Pradesh, there are two Regional Centres (RCs) of IGNOU and there is one state Open University namely MPBOU is also situated to display the Central and State Governments' efforts of disseminating higher education through ODL in the tribal areas of the state (Chaturvedi and Nayak, 2017). The population of the state of MP has more than one-fifth $(21.08 \%)$ of its population constituting tribal population. On the other hand, the enrolment share of tribal population in higher education is approximately $2 \%$ which is significantly low as against the population share of tribal people. RC of IGNOU situated at Bhopal, the state capital of MP, caters to the educational needs of 31 districts of MP through 150 Study Centres of different categories with a portfolio of more than 50 programs in its bid to reach the every unreached section of the society as it serves in one of the most disadvantaged socio-economic set-ups across the country with 10 districts having more than $25 \%$ tribal population (Figure 4).

Table 1 displaying the enrolments in these 10 most tribal dominated districts with population having more than $25 \%$ tribal population under the jurisdiction of IGNOU RC, Bhopal indicates the trend of admission which leaves a lot to be desired showing the little presence of IGNOU as the study centers in these tribal dominated areas have not been able to increase enrolment despite huge potential reflected in the population in these areas. The dismal performance might be because of poor level of sensitization/awareness as regards program offered by IGNOU and inadequate usage of ICT initiatives which IGNOU at national level has conceptualized and implemented recently.

The target population not only represents vulnerable groups but also groups not capable of making rational assessment of their problems and the solutions lying in the higher education. The tribal youth should not be kept deprived of the opportunities to learn Western Modern Science (WMS); and it must also be ensured that providing WMS should not alienate them or deprive them from the opportunities of possessing their own TEK (Aikenhead, 1997).

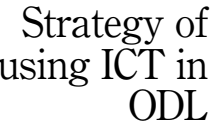




\section{AAOUJ 15,2}

200

Figure 4.

Most Tribal Dominated Districts of MP under the jurisdiction of IGNOU RC, Bhopal (MP)

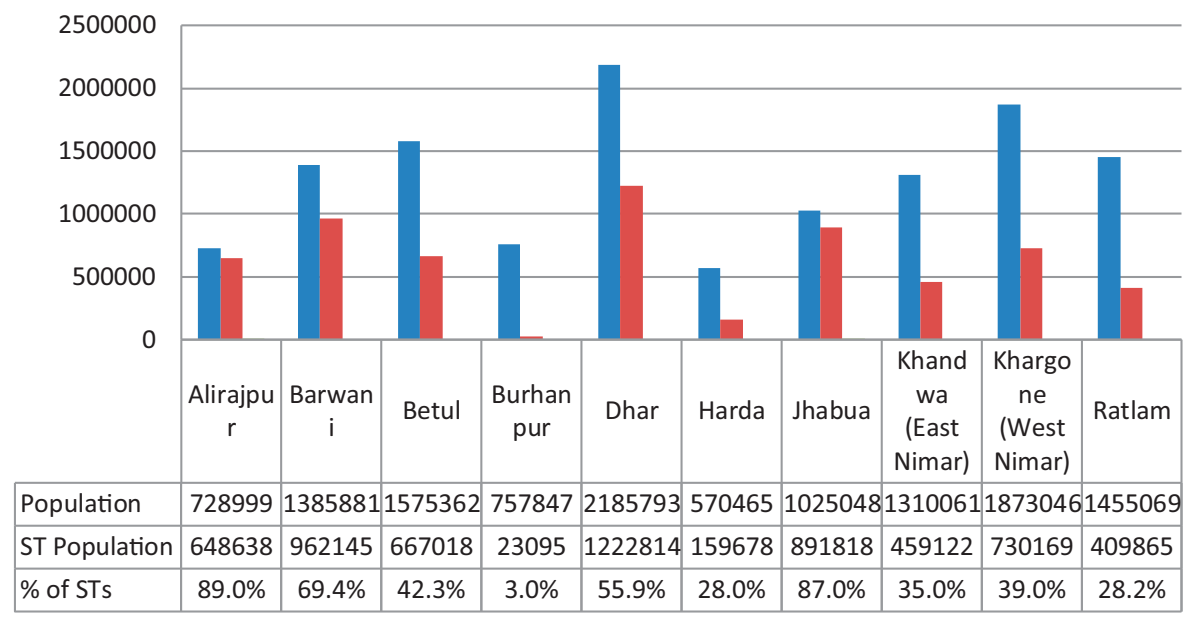

Source(s): Census of India, 2011

\begin{tabular}{llrrrrrr}
\hline S. No. & Districts & 2014 & 2015 & 2016 & 2017 & 2018 & Total \\
\hline 1 & Alirajpur & 69 & 201 & 133 & 129 & 86 & 618 \\
2 & Barwani & 32 & 34 & 07 & 10 & 13 & 96 \\
3 & Betul & 11 & 26 & 06 & 15 & 22 & 80 \\
4 & Burhanpur & 06 & 05 & 02 & 09 & 16 & 38 \\
5 & Dhar & 75 & 74 & 24 & 43 & 203 & 420 \\
6 & Harda & 01 & 02 & 00 & 03 & 00 & 06 \\
7 & Jhabua & 88 & 137 & 41 & 30 & 90 & 386 \\
8 & Khandwa(East Nimar) & 10 & 11 & 11 & 23 & 28 & 73 \\
9 & Khargone(West Nimar) & 26 & 36 & 26 & 25 & 31 & 144 \\
10 & Ratlam & 03 & 03 & 01 & 03 & 07 & 17 \\
& Total & 321 & 529 & 251 & 290 & 486 & 1878
\end{tabular}

Table 1.

District-wise

Enrollment status of ST students during 2014-2018

Source(s): Data requested and received from Regional Centre, Bhopal

Here, ICT can be used effectively for the purpose of sensitizing them to avail themselves of these efforts made by Governments intended to give them support for equipping them with necessary knowledge and skills for their sustainable livelihood and future in their own locations. ICTs can be put to use in ODL system for solving the problem in two ways, first by taking it into account as starting point to seek a problem to enhance knowledge and second by using knowledge and experience to solve a problem through development of a solution, coined as "technology first-problem second" and "problem first-technology second" respectively. The variety of challenges and constraints with respect to infrastructure, socio-economic, physical and linguistic hurdles, fewer teachers, quality, time and distance for such Indian learners posing as major concern can be tackled by appropriate use of ODL system (Bhattacharya and Sharma, 2007; McGorry, 2002) supported by effective and efficient usage of ICTs. They have their own compulsions putting restricting on their travelling long distances and spending hard earned money in order to find and approach study centers of IGNOU mostly located in urban areas. Figure 5 throws light on the poor participation of STs in the total enrolment indicating that total enrollment in the year 2014 i.e. 7,118 had only 608 


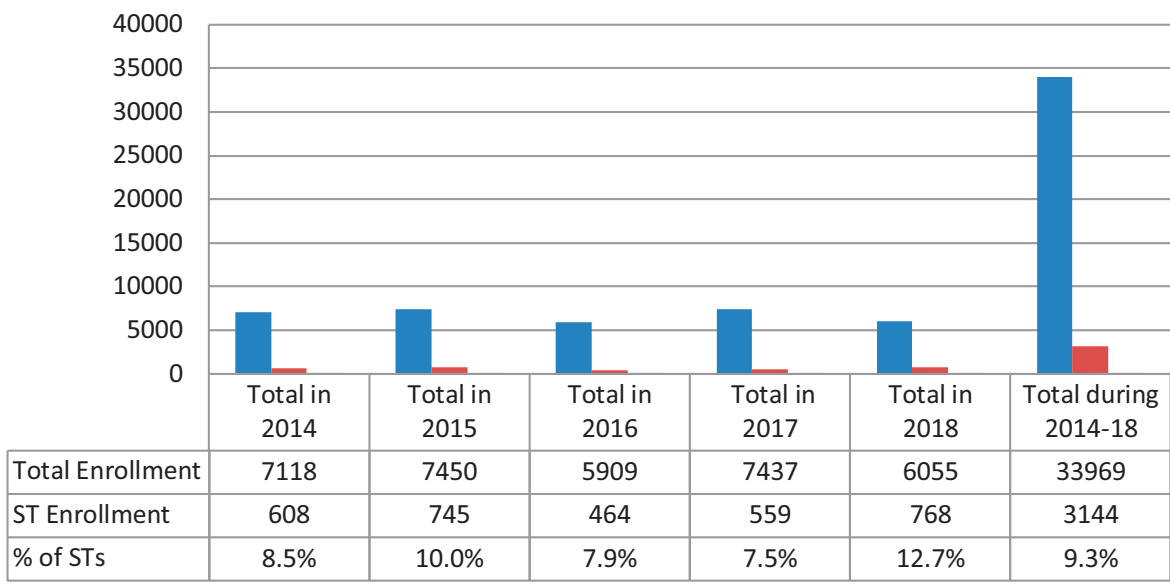

Source(s): Datarequested and received from Regional Centre, Bhopal
Strategy of using ICT in ODL

201

Figure 5.

Participation of STs in the total enrolment during 2014-2018

students from ST population which shows a poor percentage of their participation at meager $8.5 \%$. In the year 2015 too, the total enrollment was 7,450 against which 745 i.e. $10 \%$ students were from ST population, showing a slight increase of their participation. However, the temporary increasing trend did not continue as in the following year 2016, the participation of ST students were as low as $7.9 \%$ with the number 464 against the total enrolment of 5,909. Their participation remained low in the succeeding year 2017 too with the 559 enrolments against total enrolment of 7,437 showing a poor percentage of $7.5 \%$, the lowest year-wise participation during the period under study. However, the trend appears to be reversing and moving northward in the most recent year under study, i.e. 2018 in which against the total enrollment of 6,055, the participation of the ST learners in terms of their enrolment stood at $12.7 \%$ with 768 enrolments which may cause us to believe that there was a remarkable growth in their participation. The data for the entire period under study, i.e. 2014-2018 indicate that the participation of ST learners remained at $9.3 \%$ with 3,144 enrolments against the total enrolment of 33,969 in these ten most tribal dominated districts under the jurisdiction of IGNOU RC Bhopal, MP.

The data in Figure 5 clearly indicate that the situation calls for immediate special attempts for bringing this community to the mainstream of higher education arena. The poor participation of STs in the total enrolment has been an urging factor for IGNOU RC Bhopal to take a slew of initiatives including but not restricted to engaging community representative organizations for seeking their attention towards its innovative initiative of using Mobile e-Learning Terminal (MeLT) launched with the intention to enhance the reach of its student support services to remotely situated tribal areas where these mobile learning vans equipped with computers with necessary accessories and multimedia system are put to use.

Although IGNOU RC Bhopal has been resorting to several initiatives for building rapport with them engaging their representative organizations and providing them with suitable oneto-one guidance in real life setting, such as "Khula Munch" to conduct face-to-face meetings, these efforts have not been able to increase their participation remarkably. These efforts comprising presentations of the programs and policies, interactions and discussions with the stakeholders including prospective learners in such open session might bring about transformation in the enrolment trends, in days to come proving to be useful for their capacity and confidence building, if supported by the optimum utilization of the usage of ICT. 
AAOUJ

15,2
The remarkably increased percentage of participation of ST learners in the enrolment in the year 2018 at $12.7 \%$ shows silver lining. This increase can partially be attributed to the effect of the Notification No. IG/PDD/2016/353 issued on 12th May, 2016 vide which the Planning and Development Division of IGNOU recommended Direct Benefit Transfer (DBT) Scheme under the SCSP and TCP plan grants for the financial year 2016-17 for providing fee exemption of program for students belonging to SC/ST Category freshly registered in different programs such as BDP (B.A./B.Com./ B.Sc.), BSW, BTS \& BSW and re-registered students in BDP (B.A./B.Com./B.Sc.), BSW, BTS \& BCA who were newly registered in July, 2015 and January, 2016 session. However, the extensive usage of ICT by IGNOU RC Bhopal (MP) in giving wide publicity to the scheme of fee exemption introduced on pilot basis initially for the sessions July-2016 and January-2017, can also be considered to be a reason for increased enrolment of ST learners which include usage of electronic media and SMS services for the targeted awareness and sensitizing campaigns in various area of these tribal dominated districts falling under its jurisdiction.

High dropout rates in the schools in tribal areas are largely attributed to their severe indigence, want of positive motivation for education, lack of adequate educational infrastructure in their neighborhood, deficiency in communication system, and the rising cost of education which largely showcase the geographical and financial obstacles. IGNOU, since inception, has worked to ensure offering innovative and need-based affordable high quality higher educational opportunities reaching the unreached, making efforts to build a knowledge society by means of inclusive education. While the Commonwealth of Learning (COL), Canada, has accorded the Award of Excellence to it recognizing its role as a world leader in ODL, IGNOU secured 165th ranking amongst Indian websites in the Webometric ranking in 2020 showcasing its remarkable impact-openness-excellence and its focus on technologyenabled education. With 5 DTH Educational Channels under SWAYAM PRABHA, a Govt. of India initiative, it has actively been engaged in the production of tele-lectures to increase equitable access to quality education through ODL (IGNOU, 2020). IGNOU offerings such as bridge program called Bachelor Preparatory Programme (BPP) with the eligibility being attainment of the age of 18 years with no requirement of formal education, the medium of instructions being seven regional languages of India in addition to English and Hindi, the duration to complete being 06 months-24 months, and the total fee being INR 1000 only, give learners the freedom and flexibility regarding course combinations and eligibility for further higher studies. Another program, to name a few, is Computer Literacy Programme (CLP) with the eligibility being formal completion of $10+2$ which can enhance the capacity of the learners by providing them basic computer literacy. IGNOU RC Bhopal has ensured to extend academic support services right at their doorsteps or in their neighborhood villages of these tribal communities using the strength of the approved academic counselors by using MeLT van. IGNOU RC Bhopal also prepared the academic counseling schedule adhering to the prescribed norms and arranged to send its officials along with the MeLT Van keeping in view the economic conditions of these communities restricting their mobility for the purpose of saving their hard earned money. Use of MeLT van and trained/experienced subject experts are expected to bring qualitative transformation in their existing knowledge base and education level. By doing so, it is being ensured that the tribal communities are able to attain multifarious fluency where education has the responsibility of facilitating this process keeping them connected to their own communities having possessions of not only the dominant knowledge but their own cultures' knowledge, too (Brayboy and Castagno, 2008), and ODL here should come forward to lend its supporting hands by adopting the strategy of using ICT for dissemination of higher education in tribal communities, as IGNOU RC Bhopal is striving. The efforts being put in by the IGNOU $\mathrm{RC}$ Bhopal can be expected to start reflecting positive signs in the enrolment trends in the state of MP with the strategy of using ICT effectively and efficiently. 


\section{Discussions and conclusion}

Bordoloi (2018) posits that an ODL institution should have the vision of focusing on and fulfilling local needs and should design need-based and skill-based courses accordingly for transforming and empowering the learners in a country like India (Bordoloi, 2018). Tribal people along with their traditional knowledge including TEK, despite knowing about the competitiveness embedded therein, fear that they might lose it and therefore hesitate to share it with outsiders due to lack of trust and time for engaging in such activities (Ayub et al., 2018). Most of the tribes tend to engage their children for ancillary services that would bring in some added income for their starving families instead of facilitating them to enroll for higher education. IGNOU has made sincere attempt to disseminate higher education by establishing special study centers in tribal areas and using ICT applications, taking care of the challenges related to access and limited bandwidth, strategically in disseminating higher education to them at their doorstep for their empowerment and development. Dependence of the evolution of traditional knowledge including TEK possessed by tribal communities on the need to feed - clothe-transmit unique values through successive generations over thousands of years can be helpful if greater engagements of tribal communities are enhanced more particularly for climate mitigation and adaptation actions while attempting to meet the SDGs related to education, equity, equality, inclusiveness and partnerships with the effective use of ICT eliminating constraints and enhancing access and capacity in the era of knowledge and technology-based economy (Kant, 2020).

Bordoloi (2020) highlights that in the modern educational contexts, multiple opportunities have emerged for using the features of ICT to transform social settings with its increasingly higher levels of interventions in education supported by the findings of the studies particularly in the developed countries with education being delivered online in excess of $70 \%$ showing silver lining to developing countries such as India where its popularity and accessibility are yet to reach the desired speed and scale to serve the larger varied sections of learners. IGNOU through its RC Bhopal has been striving to provide the tribal youth with the opportunities to get higher education at their doorstep in order to help them learn WMS without alienating them from their own traditional knowledge including TEK. These efforts intend to help them attain multifarious fluency with the help of the usage of ICT by the ODL system. ODL system has the responsibility of facilitating their learning process without disconnecting them from their own communities and without depriving them of their dominant knowledge as well as their own cultures' knowledge. RC Bhopal of IGNOU in the state of MP has been striving to lend them supporting hands by adopting the strategy of using ICT for dissemination of higher education in tribal communities and these efforts can be expected to start showing reflecting positive signs in terms of increasing tribal enrolment trends in the state. Kant (2019) emphasizes on the importance and contributions of various important and influential stakeholders for the success of ODL system in achieving its objectives. Keeping in view that ICT interventions in ODL system play a pivotal role in the teaching-learning process today, the plethora of meaningful initiatives taken up by IGNOU to disseminate higher education to tribal communities in remote areas by providing it at their doorstep or in neighborhood areas can ensure desired level of participation of tribal learners in higher education in the state of MP, the most tribal dominated state of India, in near future. The findings of this study assure that geographical and financial constraints, which these ST communities have been faced with, can be effectively addressed by ODL system which can play important role in penetrating these tribal dominated areas with higher education with the effective and efficient intervention of ICT making higher education available at their doorsteps. However, caution and carefulness in the selection of academic counselors with minimum required technology expertise need to be given special attention by prioritizing such selections from their own communities. 
AAOUJ

15,2

204

\section{References}

Abeywardena, I.S. (2017), "An empirical framework for mainstreaming OER in an academic institution”, Asian Association of Open Universities Journal, Vol. 12 No. 2, pp. 230-242, doi: 10. 1108/AAOUJ-11-2017-0036.

Aikenhead, G.S. (1997), "Toward a first nations cross-cultural science and technology curriculum", Science Education, Vol. 81 No. 2, pp. 217-238.

Ayub, Y.I.R., Kogeda, O.P. and Lall, M. (2018), "Capturing tacit knowledge: a case of traditional doctors in Mozambique", SA Journal of Information Management, Vol. 20 No. 1, pp. 1-8.

Barney, J.B. (1991), "Firm resources and sustained competitive advantage", Journal of Management, Vol. 17 No. 1, pp. 99-120.

Bhattacharya, I. and Sharma, K. (2007), "India in the knowledge economy - an electronic paradigm", International Journal of Educational Management, Vol. 21 No. 6, pp. 543-568.

Bordoloi, R. (2018), "Transforming and empowering higher education through open and distance learning in India", Asian Association of Open Universities Journal, Vol. 13 No. 1, p. 2018, doi: 10. 1108/AAOUJ-11-2017-0037.

Bordoloi, R. (2020), "Lifelong learning opportunities through MOOCs in India”, Asian Association of Open Universities Journal, Vol. 15 No. 1, pp. 83-95, doi: 10.1108/AAOUJ-09-2019-0042.

Brayboy, B.M.K.J. and Castagno, A.E. (2008), "How might Native science inform 'informal science learning'?", Cultural Studies of Science Education, Vol. 3 No. 3, pp. 731-750.

Brown, T.H. (2006), "Beyond constructivism: navigationism in the knowledge era", On the Horizon, Vol. 14 No. 3, pp. 108-120.

Chaturvedi, A. and Nayak, S.R. (2017), "Assessment of propagation of higher education through ODL in tribal districts of Madhya Pradesh", Asian Journal of Distance Education, Vol. 12 No. 2, pp. 37-48.

Etchart, L. (2017), "The role of indigenous peoples in combating climate change", Palgrave Commun, Vol. 3, pp. 1-4.

Faridi, M.R. and Ouseph, S.N. (2014), "New directions and challenges for ODL: building collaborative business approach", European Scientific Journal, Vol. 1 Special, pp. 217-223.

Finn, S., Herne, M. and Castille, D. (2017), "The value of traditional ecological knowledge for the environmental health sciences and biomedical research", Environmental Health Perspectives, Vol. 125 No. 8, pp. 1-9.

Gaba, A. and Li, W. (2015), "Growth and development of distance education in India and China: a study on policy perspectives", Open Praxis, Vol. 7 No. 4, pp. 311-323.

Garg, S., Venkaiah, V., Puranik, C. and Panda, S. (2006), Four Decades of Distance Education in India: Reflections on Policy and Practice, Viva Books Private, New Delhi.

Harisha, R.P., Padmavathy, S. and Nagaraja, B.C. (2016), "Traditional ecological knowledge (TEK) and its importance in South India: perspective from local communities", Applied Ecology and Environmental Research, Vol. 14 No. 1, pp. 311-326.

Hitt, M.A., Ireland, R.D., Camp, S.M. and Sexton, D.L. (2001), "Strategic entrepreneurship: entrepreneurial strategies for wealth creation", Strategic Management Journal, Vol. 22 No. 6, pp. 479-492.

IGNOU (2013), IGNOU Profile 2013, Indira Gandhi National Open University, New Delhi.

IGNOU (2014), IGNOU Profile 2014, Indira Gandhi National Open University, New Delhi.

IGNOU (2020), IGNOU Profile 2020, Indira Gandhi National Open University, New Delhi.

ILO (2017), Indigenous Peoples and Climate Change: From Victims to Change Agents through Decent Work, International Labour Office, Gender, Equality and Diversity Branch, p. 43, available at: https://www.ilo.org/wcmsp5/groups/public/—dgreports/-gender/documents/publication/ wcms_551189.pdf (accessed 28 May 2019). 
ILO (2018), "Who are the indigenous and tribal peoples?", available at: https:/www.ilo.org/global/ topics/indigenous-tribal/WCMS_503321/lang-en/index.htm (accessed 24 May 2019).

Jayaram, N. (2007) Forest, J.J.F. and Altbach, P.G. (Eds), International Handbook of Higher Education, Part Two: Regions and Countries, Springer Netherlands, Dordrecht.

Jung, I. (2005a), "Cost-effectiveness of online teacher training", Open Learning, Vol. 20 No. 2, pp. 131-146.

Jung, I. (2005b), Innovative and Good Practices of Open and Distance Learning in Asia and the Pacific (Series:APEID, UNESCO Bangkok Occasional Paper Series), International Christian University, Tokyo.

Kant, N. (2019), "Competitiveness in ODL from stakeholders' perspective: a review and research Agenda", The Turkish Online Journal of Distance Education, Vol. 20 No. 3, pp. 59-72.

Kant, N. (2020), "Blockchain: a resource of competitive advantage in open and distance learning system", in Sharma, R.C., Yildirim, H. and Kurubacak, G. (Eds), Blockchain Technology Applications in Education, IGI Global, pp. 127-152, doi: 10.4018/978-1-5225-9478-9.ch007.

Kant, N. and Anjali, K. (2020), "Climate strategy proactivity (CSP): a stakeholders-centric concept", in Filho, W.L., et al. (Eds), Encyclopedia of the UN Sustainable Development Goals. Partnerships for the Goals, Springer Nature, Switzerland AG.

Karlsson, B.G. (n.d), "Asian indigenousness: the case of India”, Indigenous Affairs, available at: https:// www.iwgia.org/images/publications//IA_3-08_India.pdf (accessed 28 May 2019).

Kim, E.J.A., Asghar, A. and Jordan, S. (2017), "A critical review of traditional ecological knowledge (TEK) in science education", Canadian Journal of Science, Mathematics, and Technology Education, Vol. 17 No. 4, pp. 258-270.

McGorry, S.Y. (2002), “Online, but on target?”, Internet-based MBA Courses - A Case Study', Internet and Higher Education, Vol. 5 No. 2, pp. 167-175.

McKeown, M. (2012), The Strategy Book, 2nd ed., Pearson, Edinburgh Gate, Harlow.

McQuaide, S. (2009), "Making education equitable in rural China through distance learning", International Review of Research in Open and Distance Learning, Vol. 10 No. 1, pp. 1-21.

Menguc, B., Auh, S. and Ozanne, L. (2010), "The interactive effect of internal and external factors on a proactive environmental strategy and its influence on a firm's performance", Journal of Business Ethics, Vol. 94 No. 2, pp. 279-298.

MHRD (2016), All India Survey on Higher Education (2015-2016), Department of Higher Education, MHRD, Govt. of India, New Delhi, available at: http://mhrd.gov.in/sites/upload_files/mhrd/files/ statistics/AISHE2015-16.pdf.

Mooij, T. (2007), "Design of educational and ICT conditions to integrate differences in learning: contextual learning theory and a first transformation step in early education", Computers in Human Behavior, Vol. 23 No. 3, pp. 1499-1530, doi: 10.1016/j.chb.2005.07.004.

Negi, V.S., Maikhuri, R.K., Pharswan, D., Thakur, S. and Dhyani, P. (2017), "Climate change impact in the western Himalaya: people's perception and adaptive strategies", Journal of Mountain Science, Vol. 14 No. 2, pp. 403-416.

Pedro, F. (2001), "Transforming on-campus education: promise and peril of information technology in traditional universities", European Journal of Education, Vol. 36 No. 2, pp. 175-187, doi: 10.1111/ 1467-3435.00058.

Pegu, U.K. (2014), "Information and communication technology in higher education in India: challenges and opportunities", International Journal of Information and Computation Technology, Vol. 4 No. 5, pp. 513-518.

Porter, M.E. (1980), Competitive Strategy, Free Press, New York.

Pugoy, R.A.D.L., Habito, C.D.L. and Figueroa, R.B. Jr (2016), "Hybrid online / offline mobile solutions for accessing open educational resources in areas with poor internet connectivity", Asian 
AAOUJ 15,2

\section{6}

Association of Open Universities Journal, Vol. 11 No. 2, pp. 182-196, doi: 10.1108/AAOUJ-092016-0030.

Salick, J. and Byg, A. (2007), Indigenous Peoples and Climate Change, Tyndall Centre Publication, Oxford.

Schmidtlein, F. and Taylor, A. (2000), "Identifying costs of instructional technology in higher education”, Tertiary Education and Management, Vol. 6 No. 4, pp. 289-304, doi: 10.1080/ 13583883.2000.9967031.

Shrestha, S., Moore, J.P. and Abdelnour-Nocera, J. (2010), "Offline mobile learning: open platforms for ICT4D", 10th IEEE International Conference on Advanced Learning Technologies, pp. 703-704.

Siaciwena, R. and Lubinda, F. (2008), "The role of open and distance learning in the implementation of the right to education in Zambia", International Review of Research in Open and Distance Learning, Vol. 9 No. 1, pp. 149-186.

Tait, A. (2018), "Open Universities: the next phase", Asian Association of Open Universities Journal, Vol. 13 No. 1, pp. 13-23, doi: 10.1108/AAOUJ-12-2017-0040.

UGC (n.d), "Growth of ODL system in higher education", available at: https://www.ugc.ac.in/deb/pdf/ growthDEB.pdf (accessed 11 July 2018).

UN SDG Knowledge Platform (n.d), "Sustainable development goals", available at: https:// sustainabledevelopment.un.org/sdgs (accessed 19 May 2019).

UNEP (2013), UNEP Annual Report 2013, Nairobi.

UNESCO (1997), "Open and distance Learning: prospects and policy considerations”, p. 45, available at: http://unesdoc.unesco.org/images/0011/001107/110752E.pdf (accessed 13 July 2018).

UNESCO (2002), Open and Distance Learning: Trends, Policy and Strategy Considerations, Paris.

Ural, O. (2007), "Attitudes of graduate students toward distance education, educational technologies and independent learning", The Turkish Online Journal of Distance Education, Vol. 8 No. 4, pp. 34-43.

Wolcott, L.L. (2003), "Dynamics of faculty participation in distance education: motivations, incentives, and rewards", in Moore, M.G. and Anderson, W.G. (Eds), Handbook of Distance Education, Lawrence Erlbaum Associates, London Mahwah, NJ, pp. 549-565.

\section{Corresponding author}

Nikhil Kant can be contacted at: Nikhilkant25apr@gmail.com

For instructions on how to order reprints of this article, please visit our website:

www.emeraldgrouppublishing.com/licensing/reprints.htm

Or contact us for further details: permissions@emeraldinsight.com 